\title{
Assessing general practitioners' care of adult patients with learning disability: case-control study
}

Primary Care,

Social Medicine, University of Bristol, Bristol BS8 2PR Michael Whitfield, senior lecturer

Norah Fry Research Centre, Department of Mental Health, University of Bristol, Bristol

Oliver Russell, reader

School of Political Studies,

University of Bristol Joan Langan, research associate

Correspondence to: Dr Whitfield

Accepted for publication 4 August 1995

\begin{abstract}
Objective-To compare general practitioners' care of adult patients with learning disability with that of control patients in the same practice.

Design-Case-control study of patients and controls by a structured interview study of general practitioners.

Setting-Avon.

Patients-78 adult patients with learning disability and 78 age and sex matched controls - cared for by 62 general practitioners.

Main measures-Number and content of consultations and opinions of the general practitioners.

Results-There were more consultations for diseases of the central nervous system and of the skin among the patients than the controls (15 $v 3$ for central nervous system disease and $15 v 4$ skin disease). There were also significantly fewer recordings of blood pressure and cervical cytology tests (34 $v 51$ for blood pressure and $2 v 18$ for cytology). Although more patients were taking drugs affecting the central nervous system (33 v 6), more controls were taking drugs for musculoskeletal complaints (17 $v 7)$.

Conclusions-Although adult patients with learning disability consult with their general practitioners at equivalent rates to other patients, they get less preventive care and consult for different types of problems than do other patients. The reasons for these differences in preventive care are not clear. Carers and general practitioners should be informed of these differences to ensure that appropriate care is given.

(Quality in Health Care 1996;5:31-35)
\end{abstract}

Keywords: learning disability, general practice care, case-control study.

\section{Introduction}

General practitioners in the United Kingdom have a defined patient population and are contractually obliged to provide appropriate primary care to all of these patients. Certain population groups, such as those with particular disabilities, have been reported as finding it difficult to obtain appropriate medical care. Reasons for this include problems of gaining access to medical care, attitudes and competence of the medical profession and other health workers to members of the population group, and the specific health needs and illness patterns of certain population groups.

We report a study of the care given by general practitioners to a small section of their patient population - that is, adult patients with learning disabilities. With the closure of many hospitals for mentally handicapped patients, patients with learning disability are increasingly having to obtain their medical care from general practitioners, and little is known about the quality of this care. Although the number of such patients on a general practitioner's personal list of patients is unlikely to exceed $2 \%$ of the total, each general practitioner is likely to look after between six and eight severely disabled patients. ${ }^{1}$ Previous studies have examined the care of patients with learning disability in day centres, ${ }^{12}$ in a hospital for mentally handicapped patients, ${ }^{3}$ after referral to a community mental handicap service, ${ }^{4}$ and in a health promotion clinic. ${ }^{5}$ They found evidence that important medical problems were not recognised, treated, or adequately managed, ${ }^{1245}$ and opinion differed about whether patients with learning disability had lower consultation rates with general practitioners than did other patients. ${ }^{2-4}$

The quality of primary medical care given to patients who share diagnostic or demographic characteristics can be assessed in several ways. The most usual method is to review the medical records of a sample of such patients or to interview or examine patients and determine whether care, in the opinion of the examiner, is appropriate and at a standard acceptable to the profession. This type of assessment may provide useful information, but it can be criticised because it takes no account of difficulties in providing such care in particular situations and it assumes that the examiner and the professional carer share the same objectives. Specialists will always be able to find deficiencies in the care given by generalists to patients with diseases that fall within their specialty. The case-control method is a way of assessing quality of care in primary care and enables health professionals to be challenged by differences that are found between the care given to a group of patients sharing a characteristic feature and that given to the rest of the population. The advantage of this method of assessing quality of care is that it allows the care given by many general practitioners to a particular group of patients to be examined and compares the care they give to a patient of this group with an age and sex matched control patient within their practice. Even though the amount of care given to all of the patients 
registered with a particular doctor may be less than ideal, this method shows whether a particular part of the practice population is being disadvantaged.

We chose a sample of patients with learning disabilities within a health district, identified their general practitioners, and compared the care given to them with that given to age and sex matched control patients within the same practice. Practices were identified by the health authority. This study is part of a larger study ${ }^{6}$ in which subjects and carers were also interviewed.

\section{Patients and methods}

A proportional random sample of 149 adults with learning disabilities was drawn from the register of 919 patients aged 20 years and over, held by the former Bristol and Weston Health District within Avon. This register of patients had been regularly updated but was known to be inaccurate; however, it contained a large proportion of such patients in the health district. The proportional stratification was based on sex and type of accommodation so that the final sample was similar to the sample from the original register in terms of these two variables.

The ethics committee stipulated that we should approach patients and carers through an intermediary such as a social worker, day care worker, or general practitioner.

To compare the health care given by general practitioners to patients with learning disabilities with that given to patients without such disability, the local family health services authority provided the name of a patient matched by age and sex who was registered with the same general practitioner as the index patient.

Trained interviewers visited the general practitioners and, using a structured questionnaire that had been piloted with five general practitioners, obtained from them details of their selected patient(s) with learning disabilities and one of the control patients and their views on the care of patients with learning disabilities. Each interview lasted between 30 and 40 minutes. The medical records of the index patient and that of the control patient were referred to by the general practitioner during the interview.

The questionnaire asked how long the patients had been registered; details of the patients' social background, including details of carer(s); information about degree of handicap, vision, and hearing; details of consultations and medicines prescribed over the previous year; details of preventive procedures completed; and any evidence of behavioural difficulties (appendix). Some general practitioners had more than one patient in the study, so we were able to test some of their answers for consistency.

Statistical analysis was by Wilcoxon's matched pair test between the learning disability patients and the control patients and by the McNemar $\chi^{2}$ test when appropriate. A significance level of $\mathrm{P}<0.05$ was taken to be significant.

\section{Results}

This sample of 149 people was reduced to 127 , as we were unable to contact 13 patients either because they had died or because they had been admitted to hospital; nine others were thought to be inappropriate for the study, usually because the carer or general practitioner considered that the patient would be disturbed by an interview. As a result of the stipulation of the ethics committee we were allowed access to only 90 of the 127 people $(71 \%)$ with learning disabilities, largely because of the protectiveness of informal carers or professionals. The general practitioners of the 90 patients were identified; and 62 doctors looking after 78 patients agreed to participate in the study (a general practitioner response rate of $93 \%(62 / 67))$. There were 47 male patients and 31 female patients in our sample.

\section{DESCRIPTION OF GENERAL PRACTITIONERS}

The general practitioners interviewed in the study included 12 female general practitioners, and the doctors' age distribution slightly underrepresented the young general practitioners within Avon. Most doctors (52) had been in their current practice for more than five years. Only 11 worked in practices of under 5000 patients. Twelve of the 62 general practitioners were looking after two or more patients with learning disability (two doctors had three patients and one doctor had four patients in the study). An examination of these doctors' answers to 17 of the questions (which should have received the same answer in each of the 2-4 questionnaires), showed that eight doctors answered 15 or more of the questions identically, three answering nine or 10 questions identically. This validation procedure included the answers to questions such as the size of the practice and 11 attitude questions, five of which had five point Likert scales (see appendix).

\section{GENERAL PRACTITIONERS' VIEWS ABOUT}

PATIENTS WITH LEARNING DISABILITY

The general practitioners considered that 20 of the patients had a mild learning disability, 40 a moderate learning disability, and 17 a severe learning disability; one patient's learning disability was not classified. The doctors claimed that 40 patients had normal sight and eight poor sight, but 30 patients had no information about their sight. Similar levels of knowledge existed about the patients' hearing (47, good; 15, poor; 16, no knowledge).

\section{MEDICAL CARE}

We found no significant difference in the length of time patients with learning disability had been registered with their general practitioner compared with controls (table 1), and the recorded number of consultations that both groups of patients had with general practitioners and specialists showed no significant difference (table 2).

The recorded medical problems experienced by patients with a learning disability differed in some ways from those experienced by the control patients. These problems were 
Table 1 Length of time patients had been registered with general practice

\begin{tabular}{lcccc}
\hline & No of years registered & \\
\cline { 2 - 5 } & $<1$ & $1-4$ & $5-9$ & $\geqslant 10$ \\
\hline Subjects $(\mathrm{n}=78)$ & 5 & 23 & 21 & 29 \\
Controls $(\mathrm{n}=78)$ & 3 & 14 & 24 & 37 \\
\hline
\end{tabular}

Differences between groups were not significant (Wilcoxon matched pairs test).

Table 2 Patients' contacts with doctors during previous year

\begin{tabular}{llccc}
\hline & & $\begin{array}{c}\text { Subjects } \\
(n=78)\end{array}$ & $\begin{array}{c}\text { Controls } \\
(n=78)\end{array}$ & \\
\hline No of surgery & 0 & 20 & 26 & \\
$\quad$ consultations/year: & $1-4$ & 35 & 37 & \\
& $5-9$ & 18 & 14 & $\mathrm{NS}^{\star}$ \\
& $\geqslant 10$ & 5 & 1 & $\mathrm{NS}+$ \\
$\begin{array}{l}\text { No of patients with home } \\
\text { visits }\end{array}$ & 13 & 6 & $\mathrm{NS}+$ \\
$\begin{array}{l}\text { No of patients with } \\
\text { specialist consultations }\end{array}$ & 15 & 12 & \\
\hline $\begin{array}{l}\text { NS }=\text { not significant. } \\
\star \text { Wilcoxon matched pairs test. }\end{array}$ & & & & \\
+ McNemar's $\chi^{2}$ test. & & & & \\
\end{tabular}

classified in broad diagnostic terms, and the patients with a learning disability had more diseases of the central nervous system (mostly epilepsy) and of the skin (table 3).

When the doctors were asked for an opinion on the length of consultations, patients with learning disabilities had longer consultations, but many doctors could not give an opinion (table 4). Only 11 patients with learning disability were described by the doctors as having behaved in inappropriate ways during consultations, including shouting and being abusive or demanding. However, four patients in each group were described as being "heart sink" patients.

Significantly more patients with learning disability than control patients had prescriptions during the previous 12 months for drugs affecting the central nervous system such as psychotropic and antiepileptic agents. But more control patients were taking drugs for musculoskeletal complaints (table 5).

PREVENTIVE CARE

Thirty four patients with learning disabilities and 51 controls had had their blood pressure recorded in the general practitioners' records

Table 3 Numbers of patients with diagnoses addressed during previous year

\begin{tabular}{lccc}
\hline Diagnostic group & $\begin{array}{c}\text { Subjects } \\
(n=78)\end{array}$ & $\begin{array}{c}\text { Controls } \\
(n=78)\end{array}$ & $P$ value \\
\hline Central nervous system & 15 & 3 & 0.0042 \\
Psychiatric & 8 & 3 & NS \\
Gastrointestinal (mostly & 4 & 3 & NS \\
abdominal pain) & 15 & 4 & 0.0034 \\
Dermatological & 9 & 14 & NS \\
Musculoskeletal & 2 & 8 & NS \\
Gynaecological & & &
\end{tabular}

${ }^{\star}$ McNemar's $\chi^{2}$ test.

Table 4 General practitioners' perceptions of lengths of consultations

\begin{tabular}{lccccc}
\hline & Normal & Normal & $<$ Normal & No perception \\
\hline Subjects $(\mathrm{n}=78)$ & 13 & 41 & 6 & 18 \\
Controls $(\mathrm{n}=78)$ & 4 & 36 & 8 & 30 \\
\hline
\end{tabular}

Wilcoxon matched pairs $Z=-2.4351$, two tailed $P=0.0149$.
Table 5 Number of patients taking prescribed drugs during previous year

\begin{tabular}{lccc}
\hline Drug group & $\begin{array}{c}\text { Subjects } \\
(n=78)\end{array}$ & $\begin{array}{c}\text { Controls } \\
(n=78)\end{array}$ & Pvalue \\
\hline Central nervous system & 33 & 6 & 0.000 \\
Infections & 15 & 9 & NS \\
Cardiovascular & 7 & 5 & NS \\
Musculoskeletal & 7 & 17 & NS \\
\hline
\end{tabular}

${ }^{\star}$ McNemar's $\chi^{2}$ test.

over the previous five years. Few women (two out of 22) in the appropriate age range with learning disabilities had received a cervical cytology test within the previous five years (table 6).

Even though almost one third (25/78) of the patients were stated to cause the doctors difficulty during examination, there was no association between those who caused the doctors difficulty and those who had not had the tests, implying that there were other reasons for not having been given these tests.

SOCIAL KNOWLEDGE OF THE PATIENT

The general practitioners seemed to know more about the social situation of their patients with learning disability than they did about the control patients. In answer to the question, "are there any special circumstances about X's social situation which you are aware of when treating him/her?" the doctors claimed such knowledge about 40 patients with learning disabilities compared with 28 of the control patients (table 7). The doctor knew who the patient lived with for all but six of those with learning disabilities, but they knew nothing about 26 of the control patients.

\section{Discussion}

We found that patients with learning disability consulted their general practitioners as often as the control patients. However, they consulted about different types of problems, received different types of treatment, and received significantly different preventive care from control patients. The fact that the two groups of patients had the same general practitioners may have influenced our results, but with 50 of the 62 doctors having one patient in the study, and with most of the remainder having two patients, we believe that any effect is likely to have been small.

Table 6 Numbers (percentages) of preventive procedures recorded over previous five years

\begin{tabular}{lccc}
\hline Preventive procedure & Subjects & Controls & P value \\
\hline $\begin{array}{l}\text { Blood pressure recorded in } \\
\text { records }(\mathrm{n}=78)\end{array}$ & $34(44)$ & $51(65)$ & 0.003 \\
$\begin{array}{c}\text { Cervical cytology test } \\
\text { performed by general } \\
\text { practitioner }(\mathrm{n}=22)^{\star}\end{array}$ & $2(9)$ & $18(82)$ & $<0.0001$ \\
\hline
\end{tabular}

«Three controls and one subject had had hysterectomy and had not had cytology test performed.

Table 7 General practitioners' knowledge about their patients. Values are numbers of patients

\begin{tabular}{lccc}
\hline & Subjects & Controls & $P_{\text {value }}^{\star}$ \\
\hline $\begin{array}{l}\text { Claimed knowledge of social } \\
\text { situation ( } \mathrm{n}=78)\end{array}$ & 40 & 28 & $>0.05$ \\
$\begin{array}{c}\text { Stated knowledge of who } \\
\text { patient lived with }(\mathrm{n}=78)\end{array}$ & 72 & 52 & $<0.0005$ \\
\hline
\end{tabular}

$\star$ McNemar's $\chi^{2}$ test. 
This study relied on the statements of general practitioners given to trained interviewers. The general practitioners referred to the patients' medical records during the interviews, but their statements about their perceptions of the patients' degree of handicap and the length of the average consultation can be regarded only as opinions and ideally require validating. However, assessing these features accurately and determining whether clinically significant disease is being missed would require a much more expensive investigation. Patients with learning disability are a heterogeneous group within a general practice, often being characterised by their inability to look after themselves to the same extent as age matched controls. Consequently they may be at greater risk of ill health, particularly from accidents, than are other patients in the practice, as well as having problems from coexisting chronic disease. ${ }^{12}$ With the case-control method we have found some expected differences between the care given to these patients (the subjects) and the controls such as higher diagnosis of and prescription of drugs for diseases of the central nervous system. Some authorities have expressed concern at the way some patients with learning disabilities are "controlled" with psychotropic treatment, and the prevalence of such treatment in our study indicates that general practitioners should take care when reviewing or starting it. ${ }^{78}$

The doctors' knowledge of the social circumstances of patients was greater for those with learning disability than for control patients, perhaps because many patients with learning disability were accompanied by carers and were perceived as having longer consultations than other patients. However, we found some unexpected results. We found no difference in the frequency of consultations between patients with learning disability and control patients, although Wilson and Haire found similar low consultation rates in their study. ${ }^{2}$ Fewer consultations by patients were for musculoskeletal disease, although not significantly so, but the control patients were more likely to be receiving treatment for such complaints. Perhaps adult patients with learning disability are more protected than others, are encouraged by their carers to tolerate musculoskeletal pain that other patients would take to their general practitioner, or are possibly unable to express all of their problems to their doctor. Certainly, we found no evidence that these patients have more accidents than do control patients. There were more consultations for skin disease in the subjects than in the control patients, possibly resulting from the increased use of psychotropic drugs.

Preventive procedures such as screening the population for hypertension and cervical carcinoma has been encouraged for several years. We found that patients with learning disabilities had been screened significantly less often for these conditions than had control patients. We found no evidence that this was because patients were considered difficult to examine and we wonder whether this difference may be because control patients ask for these procedures whereas patients with learning disabilities and their carers do not. One other possibility is that doctors' attitudes to patients with learning disabilities preclude them from considering preventive procedures for such patients.

Assessing the care received by patients with learning disabilities from their general practitioners in this way has shown that such patients receive similar primary care to other patients, with the exception of preventive care. However, when samples of patients with learning disabilities have been carefully examined many health problems are uncovered. ${ }^{259}$ To determine whether patients with learning disabilities really have the same care as control patients, we recommend adding a full physical examination to any future study.

Patients with learning disabilities fit badly into a health care system in which no care is received unless it is asked for. ${ }^{2}$ Like others, ${ }^{26}$ we believe that patients with learning disabilities need to have special care to ensure that they do not continue to be disadvantaged. Strategies for improving such care could be directed at the general practitioners, people with learning disabilities, carers, community learning disability teams, and health authorities.

This study was funded by the Department of Health. We thank the general practitioners for their cooperation. We also thank Anthony Hughes for statistical advice and Maggie Shapland for help with the database.

\section{Appendix}

Questions put by the interviewers to general practitioners about patients with learning disability and, apart from question 5, about control patients.

1 How many years has your practice been treating $\mathrm{X}$ ? $<1$ year, $1-<2$ years, $2-<5$ years, $5-<10$ years, $10-<15$ years, $>15$ years.

2 Are there any special circumstances about X's social situation which you are aware of when treating him/her? Yes/No. Can you tell me what these are?

3 Do you know who $\mathrm{X}$ lives with? Yes/No. Who does s/he live with?

4 What do you know about the kind of support $\mathrm{X}$ gets from others?

5 In your opinion, is X's level of handicap mild, moderate, or severe to profound?

6 Would you say that X's hearing is good, reduced, deaf, or very poor? Or would you say that you don't know?

7 Does X wear glasses? Yes/No/Don't know. Is X's sight with glasses glood/normal, reduced, blind, or very poor? Or would you say that you don't know?

8 Has X consulted you about any acute or chronic conditions, other than minor, temporary conditions, over the 12 months? Yes/No. Please list the problems which led to the consultations and say who treated them - for example, you alone or in conjunction with other professionals - and where the treatment took place.

9 How many consultations has $\mathrm{X}$ had in the past 12 months. How many were at the practice? How many were at X's home?

$10 \mathrm{Has} X$ received any drug treatment over the past 12 months? Yes/No. Can you tell me what 
treatment, including continuing treatment and repeat prescriptions, $\mathrm{X}$ has received?

11 Do you know whether $\mathrm{X}$ has had a cervical smear test or blood pressure check from a general practitioner in the past five years?

12 Does X smoke? Yes/No/Don't know.

13 Is $\mathrm{X}$ overweight? Yes/No/Don't know.

14 Do you find that your consultations with $\mathrm{X}$ take longer than average, an average amount of time, shorter than average, or that it is difficult to say because you don't see $\mathrm{X}$ much?

15 Has X ever behaved in ways which you consider inappropriate in the surgery? Yes/No/Don't know.

16 Have there been any problems about getting $\mathrm{X}$ to understand advice, take treatment, or have physical tests or examinations? Yes/No. Please could you describe any problems?

17 I would expect that you have some patients who make your heart sink when they come in for a consultation. Is $\mathrm{X}$ one of these patients? Yes $/ \mathrm{No}$.

There are also a series of questions about the general practitioner, the practice, and the primary healthcare team. These included the following.

18 Please could you indicate which one of the following age groups you belong to? 20-29; $30-39 ; 40-49 ; 50-59 ; \geqslant 60$.

19 What is your partnership list size?

20 In this section there are various statements which I would like you to consider and then indicate how far you agree or disagree with them. Please give your initial response. Responses are on a five point Likert scale.

- People with mental handicap should receive all their health services from primary health and general hospital services - that is, not from the mental handicap services

- Professionals working in the mental handicap services are experts in caring for all aspects of care for people with mental handicap

- General practitioners don't see enough mentally handicapped patients to justify going on a training course

- A caring attitude by the doctor is more important than training in the care of people with mental handicap

1 Howells G. Are the medical needs of mentally handicapped adults being met? Fournal of Royal College of General Practitioners 1986;36:449-53.

2 Wilson DN, Haire A. Health care screening for people with mental handicap living in the community. BMF 1990 301:1379-81.

3 Beckitt D, Searle GF, Wright EC. What sort of doctors do people with mental handicap need? British fournal of Clinical and Social Psychiatry 1987;5:38-42.

4 Bouras N, Drummond CR. Health care for people with mental handicap. BMF 1991;302:348

5 Beange $\mathrm{H}$, Bauman $\mathrm{A}$. Health care for the developmentally disabled. Is it necessary? In: Fraser W, ed. Key issues in mental retardation research. London: Routledge, 1990: 152-62.

6 Langan J, Whitfield M, Russell O. Paid and un-paid carers: their role and satisfaction with primary health care for people with learning disabilities. Health and Social Care in the Community 1994;2:357-65.

7 Hubert J. Too many drugs, too little care. Parents' perceptions of administration and side-effects of drugs prescribed for young of administration and side-effects of drugs prescribed for young people with severe

8 Rodgers J, Russell O. Healthy lives - the health needs of people with learning disabilities. In: Values and visions: changing ideas in services for people with learning disabilities. London: Butterworth-Heinneman, 1995;204-319.

9 Howells G. Mental handicap - care in the community. $\mathrm{Br}$ f Gen Pract 1991;42:2-4. 